\title{
Dynamic response of reinforced concrete building from the effects of rail transport
}

\author{
Ivo Demjan, Michal Tomko \\ Technical University of Košice \\ Civil Engineering Faculty, Institute of Structural Engineering \\ e-mail: ivo.demjan@tuke.sk, michal.tomko@ tuke.sk
}

\begin{abstract}
A 3D model of a reinforced concrete building and was created in software ANSYS. The dynamic analysis was focused on the spectral response of the object represented by a random excitation experiment found in records in the form of load spectra.
\end{abstract}

Key words: experiment, spectral analysis, modeling

\section{Introduction}

The conciseness of computational models should be verified based on experimental investigations of the structure. Verification is made possible by comparing measured and computational model characteristics. The model may be optimized by the results of the diagnostic methods (experimental model analysis). Experimentally determined model characteristics describe the current status, properties and spatial behaviour of the structure, respectively certain elements of the structure at the time of experimentation [1], [2]. Such a model facilitates the calculation of the response of time courses of tested specimens to dynamic effects.

\section{Measurements}

Model characteristics of real buildings can be obtained in two manners:

- The processing of the response of the structure with the aid of controlled excitation power (Forced Vibration Testing - FVT);

- The processing of structural vibrations (oscillations), which are caused by natural ambient forces (Ambient Vibration Testing - AVT). 
The role of an experimental investigation was to determine the model characteristics of reinforced concrete buildings, which were obtained from a dynamic response induced by natural ambient forces (AVT), so that in this case, ambient vibration effects spread through the natural environment because of actively used railway lines located near the monitored object. The result is the natural frequency of vibration of the building in the analysed frequency range, where obtained custom shapes of vibration from the records were suppressed by the interference of different shaped components.

The 13-storey reinforced concrete building has a height of 47,3 $\mathrm{m}$ above ground level and is fixed to a reinforced concrete slab at a depth of 4,2 m below ground level which in turn rests upon a clayey-sand to gravelly-sand subsoil. The supporting structure is made up of twenty reinforced concrete columns with dimensions of $0,5 \times 0,5 \mathrm{~m}$ and reinforced core loadbearing walls with a thickness of $0,3 \mathrm{~m}$. Floors are made of precast reinforced concrete $22 \mathrm{~cm}$ thick resting on five reinforced concrete beams with dimensions of $0,5 \times 0,5 \times 20,4 \mathrm{~m}$ capped with a reinforced concrete bond beam around the perimeter of the floor with dimensions of $0,5 \mathrm{x}$ $0,5 \mathrm{~m}$. The axial distances between the floors are 4,2 $\mathrm{m}$ for the I. and II. floor and 3,3 $\mathrm{m}$ for the other floors, figure 1.

The railway line was designed with a speed limit of $60 \mathrm{~km} / \mathrm{h}$ for all trains. The distance between the building and the railway line is $43,3 \mathrm{~m}$.

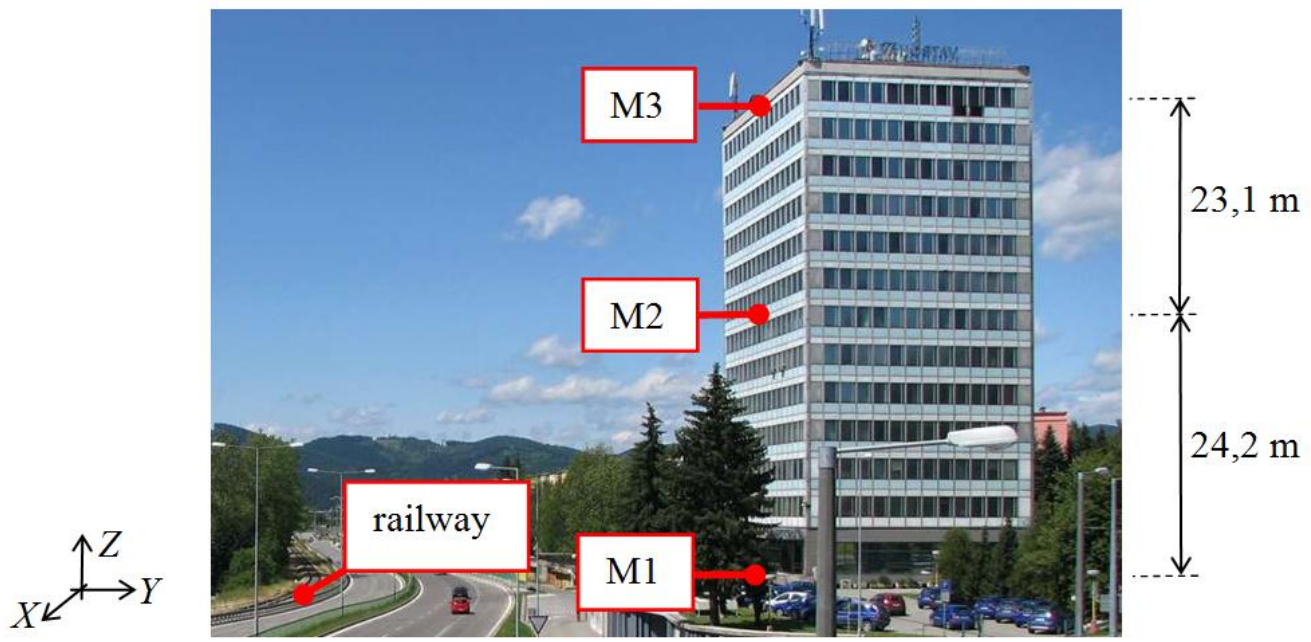

Figure 1: Situation of reinforced concrete building and railway line, distribution of measuring points: M1 - basement; M2 - 7. floor; M3 - roof

\section{Results of experimental measurements}

Dominant oscillation frequency bands of the subsoil at the base level of the reinforced concrete structure (point M1) which are induced by the effects of the rail, basically coincide in all directions. Dominant frequencies range from $9 \mathrm{~Hz}$ to $24 \mathrm{~Hz}$, with peaks at $9,1 \mathrm{~Hz}$, from 11,2 to $11,9 \mathrm{~Hz}, 13,1 \mathrm{~Hz} \sim 13,8 \mathrm{~Hz}$, and $15,1 \mathrm{~Hz}$ to $19 \mathrm{~Hz}$, but also in the range of $21 \mathrm{~Hz}$ to 23,5 Hz. This confirms not only PSD but also CPSD (figure 2, figure 3, figure 4). Transfer 
functions other than those specified in the frequency regions also show frequency bands $2 \sim$ $3,5 \mathrm{~Hz}$ and 5,2 $\sim 8 \mathrm{~Hz}$. At the same time it can be concluded that these bands represent the linear energy transfer of vibrations (oscillations) from the source to the base of the structure, as is evidenced in the coherence function.

In terms of the frequency analysis of experimentally detected signals of vibration acceleration in the dynamic response of reinforced concrete buildings, it can be concluded that the dominant frequency occurred between $1,3 \mathrm{~Hz}, 4 \sim 4,8 \mathrm{~Hz}$, with frequency bands ranging from $7 \mathrm{~Hz}$ to $9 \mathrm{~Hz}$ and above $10 \mathrm{~Hz}$. Transmission characteristics of the building refer to the frequency bands $1,2 \sim 1,5 \mathrm{~Hz}$, from $4,1 \mathrm{~Hz}$ to $4,7 \mathrm{~Hz}$, and $7 \mathrm{~Hz}$ to $10,4 \mathrm{~Hz}$ and above $13 \mathrm{~Hz}$.

Coherence functions show the linearity of oscillations in these frequency bands. The first natural frequency of oscillation experimentally observed is $f_{0(1)}^{\exp }=1,2 \approx 1,5 \mathrm{~Hz}$. From the time histories, the vibration acceleration of the dynamic response of the building was calculated by logarithmic decrement of attenuation $v_{\text {exp }}=0,0769$.

Some experimentally observed power spectral density vibrations of the structure ranged in the area of 1,2 $\sim 1,4 \mathrm{~Hz}$ which were more or less repressed and observed only in specific power spectral density oscillations. A decrease in performance vibration at a frequency that can be attributed to the observed dominant frequency domain in reference position (M1 - basement, figure 3), demonstrates the dynamic characteristics of the transmission path (natural subsoil) and dynamic excitation effect (rail transport vehicles). It can be stated that the spectra of dynamic responses of reinforced concrete buildings from the effects of rail transport vehicles reveal the influence acting seismic motion and oscillating capabilities have on the structure.

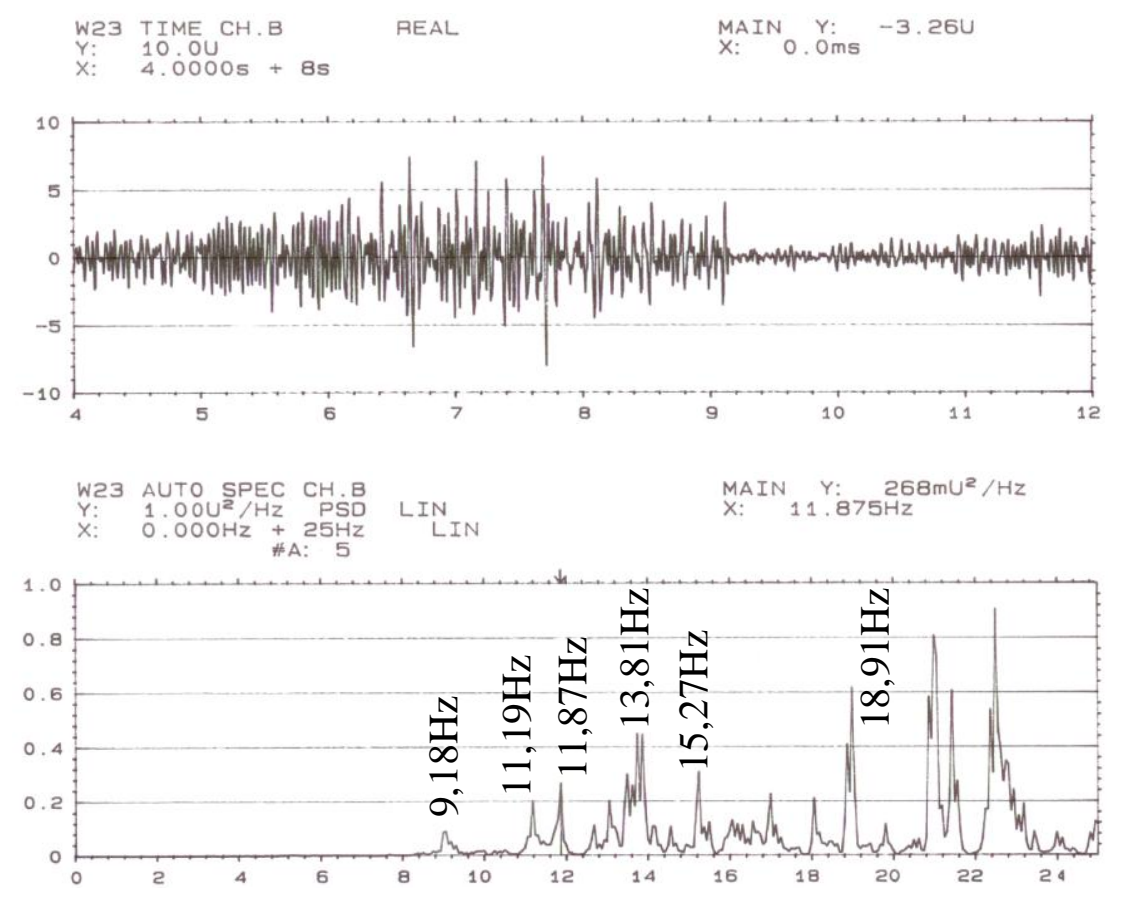

Figure 2: Vibration acceleration time history at point M1, power spectral density $\left(\mathrm{G}_{\mathrm{M} 1 \mathrm{M} 1}(\mathrm{f})\right)$ at point $\mathrm{M} 1$ - direction $\mathrm{Z}$ 


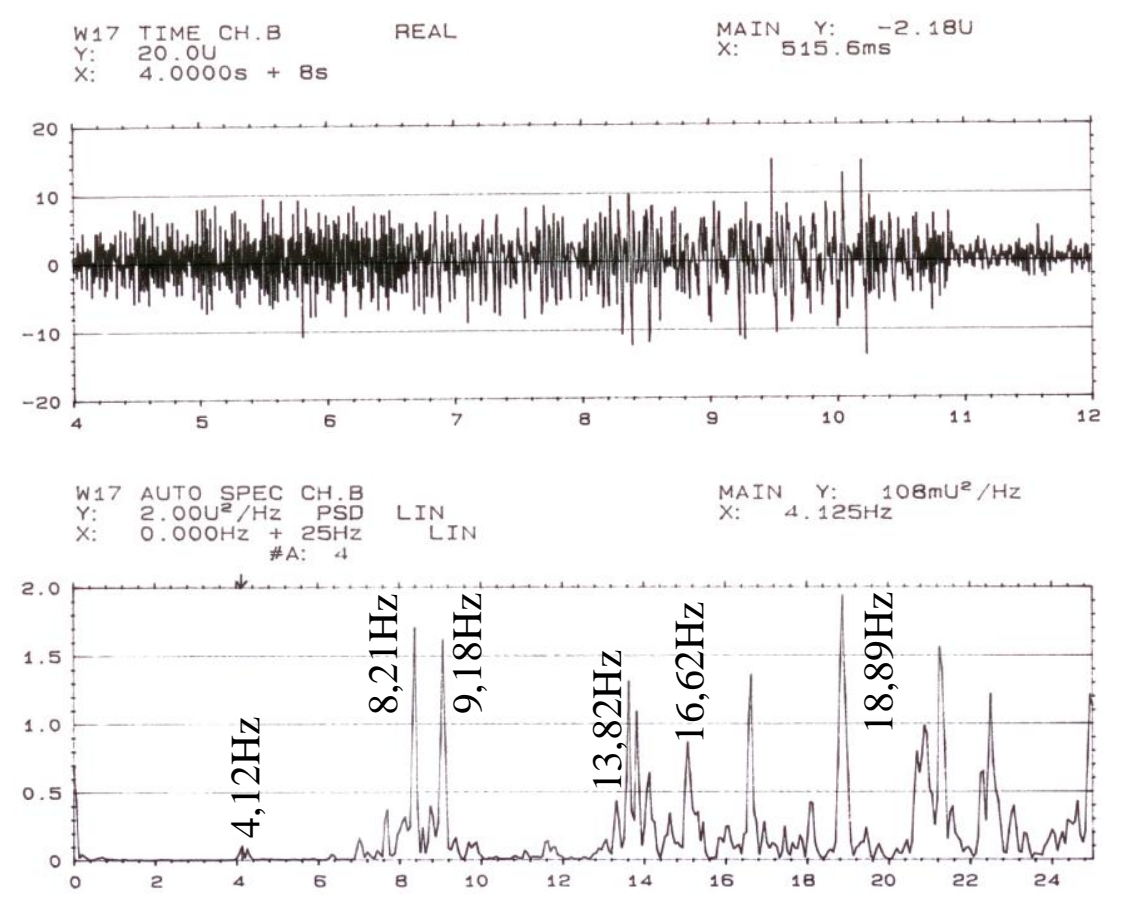

Figure 3: Vibration acceleration time history at point M2, power spectral density $\left(\mathrm{G}_{\mathrm{M} 2 \mathrm{M} 2}(\mathrm{f})\right)$ at point $\mathrm{M} 2$ - direction $\mathrm{Z}$
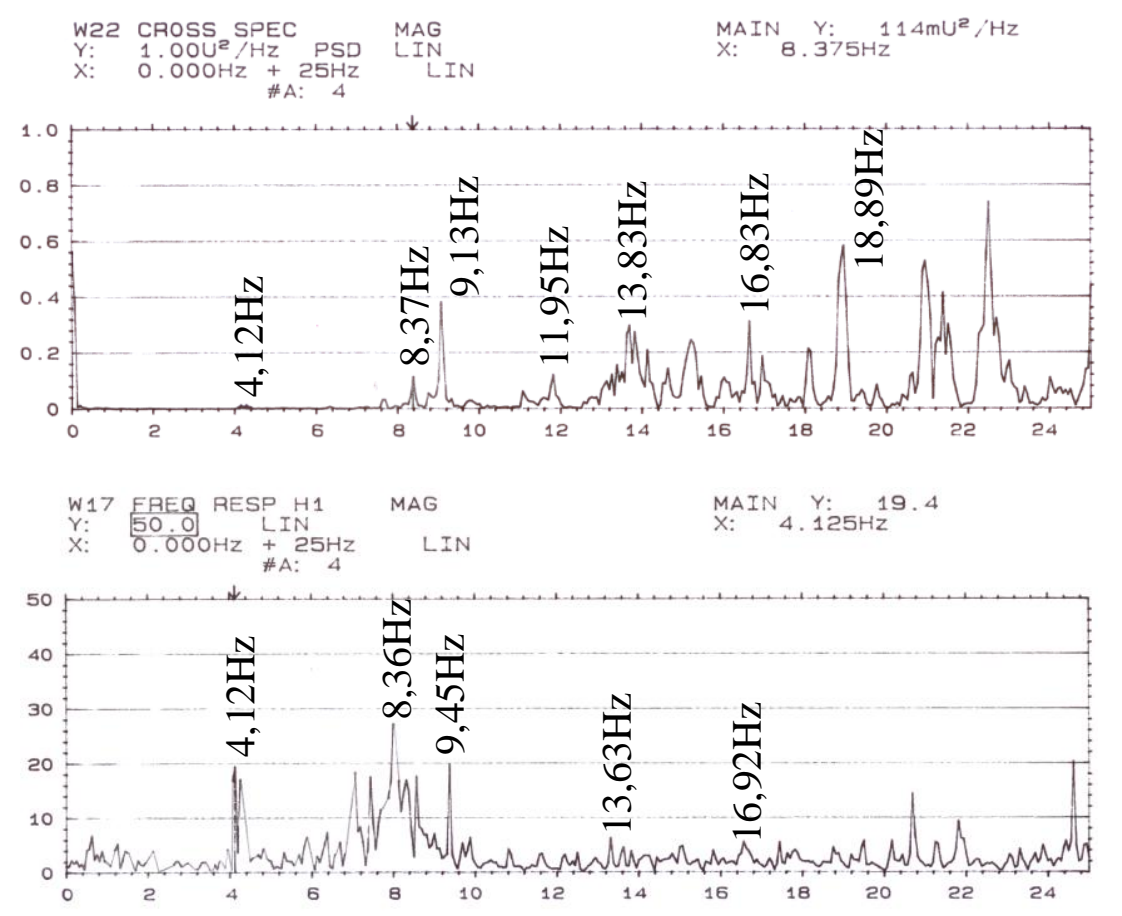

Figure 4: Cross power spectral density $\left(\mathrm{G}_{\mathrm{M} 1 \mathrm{M} 2}(\mathrm{f})\right)$, at points $\mathrm{M} 1, \mathrm{M} 2$, transfer characteristic $\left(\mathrm{H}_{\mathrm{M} 1 \mathrm{M} 2}(\right.$ if $\left.)\right)$, at points $\mathrm{M} 1, \mathrm{M} 2$ - direction $\mathrm{Z}$ 


\section{Calculation of internal oscillations}

The spatial computation model of the structure modelled all floors (slabs), foundations, columns and load bearing walls. The weight of non-load bearing elements (walls, floors and floor load equivalent utility) was added to the weight of the floor slabs. The modulus of elasticity for reinforced concrete elements (concrete C 25/30) measured E = $31000 \mathrm{MPa}$. Bulk density of the volume elements measured $\rho=2400 \mathrm{~kg} / \mathrm{m}^{3}$. Thicknesses of the loadbearing columns and walls were also included using actual values. The element Brick - Solid 45 was used in the computational 3D model of the structure which had 118380 nodes and 59 137 elements. The supporting computational model of the structure was considered as a perfect constraint.

The damping of the structure was derived from the experiment $\left(v=v_{\exp }=0,0769\right)$, creating a constant damping factor for the structure:

$$
\xi=\alpha / 2 \omega_{01}+\beta \omega_{01} / 2=0,0121
$$

Table 1 and figure 5 lists some natural frequencies for the reinforced concrete building oscillation computational model.

Table 1: Natural oscillation frequency of the calculation model

\begin{tabular}{|c|c|c|c|}
\hline Oscillation & Frequency [Hz] & Oscillation & Frequency $[\mathrm{Hz}]$ \\
\hline 1 & 1,3772 & 11 & 11,481 \\
2 & 1,8382 & 12 & 11,801 \\
3 & 2,3229 & 13 & 11,931 \\
4 & 5,2224 & 14 & 13,064 \\
5 & 6,8502 & 15 & 14,319 \\
6 & 6,9759 & 16 & 14,554 \\
7 & 8,7628 & 17 & 15,234 \\
8 & 10,319 & 18 & 16,089 \\
9 & 10,635 & 19 & 16,476 \\
10 & 11,151 & 20 & 16,683 \\
\hline
\end{tabular}

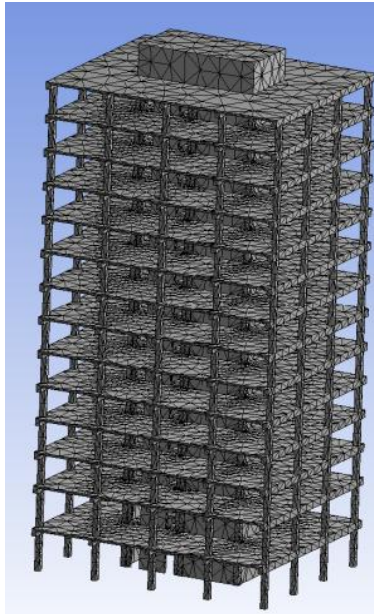

Model of the structure

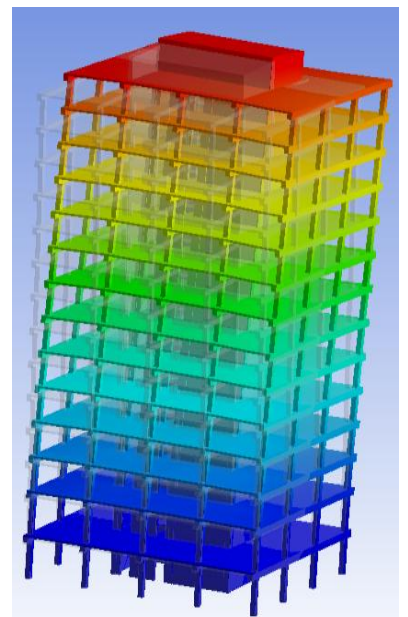

1. mode shape $\left(f_{0(1)}=1,3772 \mathrm{~Hz}\right)$ 


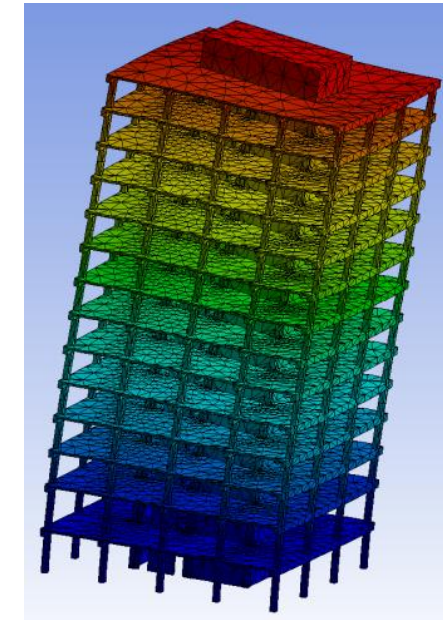

2. mode shape $\left(f_{0(2)}=1,8382 \mathrm{~Hz}\right)$

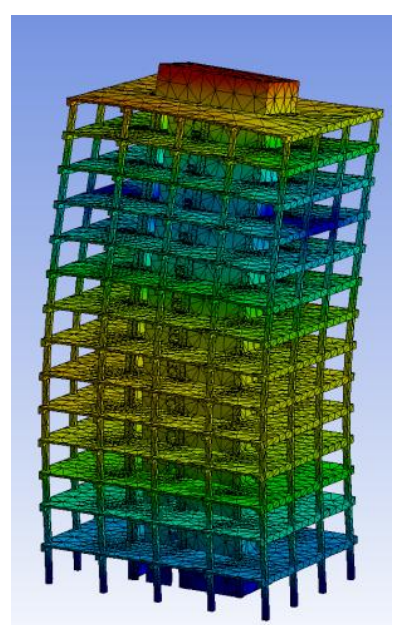

4. mode shape $\left(f_{0(4)}=5,2224 \mathrm{~Hz}\right)$

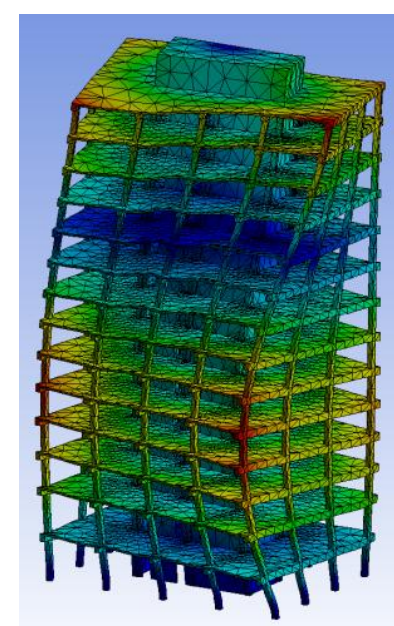

6. mode shape $\left(f_{0(6)}=6,9759 \mathrm{~Hz}\right)$

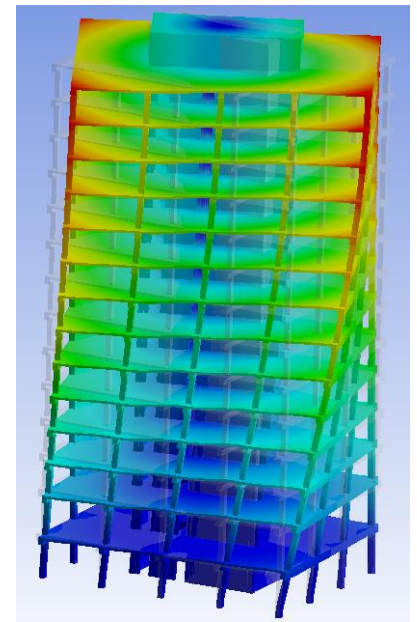

3. mode shape $\left(f_{0(3)}=3,3229 \mathrm{~Hz}\right)$

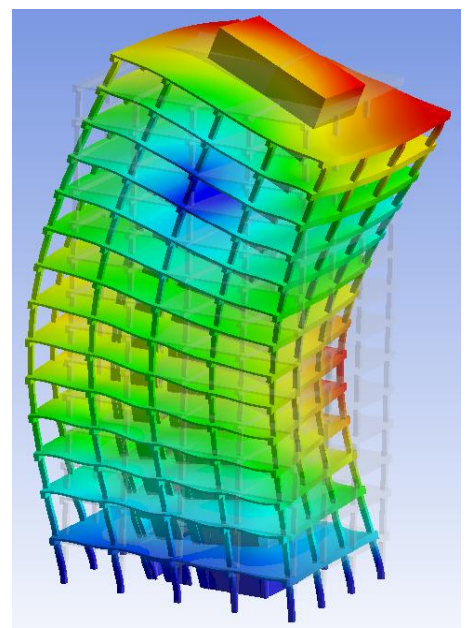

5. mode shape $\left(f_{0(5)}=6,8502 \mathrm{~Hz}\right)$

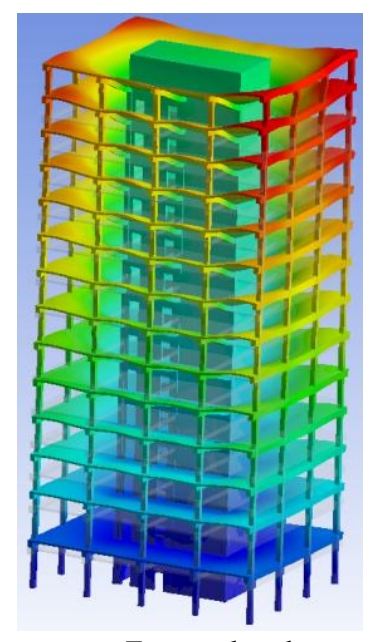

7. mode shape $\left(f_{0(7)}=8,7928 \mathrm{~Hz}\right)$

Figure 5: Natural frequencies and vibration (oscillation) shapes of reinforced concrete buildings 


\section{The dynamic response of a structure based on a theoretical and experimental approach}

ANSYS - Workbench 12.0 was used in the study, so that the results were designed to compare the experimental and theoretical approach of the dynamic response of reinforced concrete buildings. Monitored points of the dynamic response of a computational model of the structure were consistent with areas in the experimental measurements.

Micro-seismic loads were represented by modified vibration (oscillation) acceleration time histories (accelerograms) which were measured at the reference position (M1) of the structure. The computational model of the structure is burdened by the performance of the power spectral density vibration acceleration (PSD - Power Spectral Density) of the experimentally observed accelerograms at point M1. In addressing the dynamic response calculation model of the structure, the actual effect of all three components of the PSD (direction X, Y, Z) are considered.

Traces of experimentally observed vibration acceleration time histories for each $\mathrm{X}$ and $\mathrm{Z}$ directions, calculated by PSD to individual vibration acceleration time histories and histograms of vibration acceleration time histories, describe coincidental effects exerted by the rail as is shown in figure 6, figure 7, figure 8, figure 11. An approximation function describing the distribution function of the vibration acceleration time for a recorded random excitation effect of experimental measurements, which is suitable for analytical expressions of random excitation effect, figure 9 was also discovered.

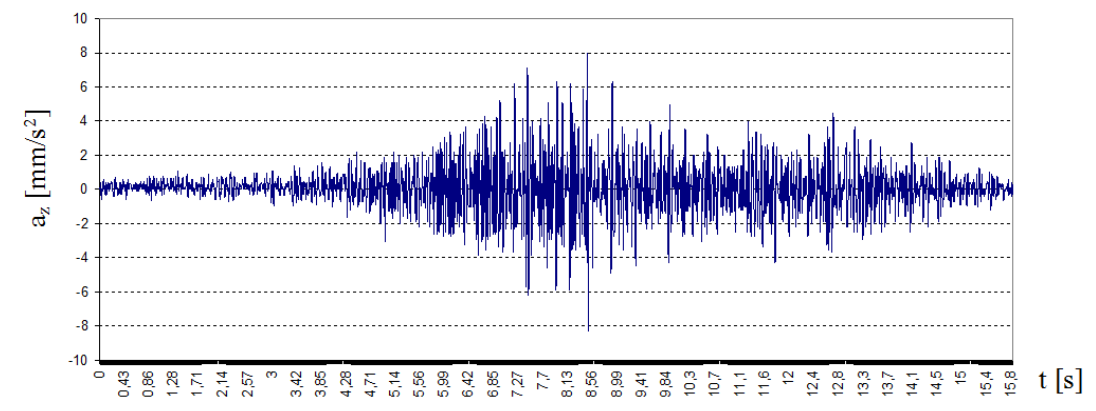

Figure 6: Time record of vibration acceleration in M1 - Z, RMS = 1,3526

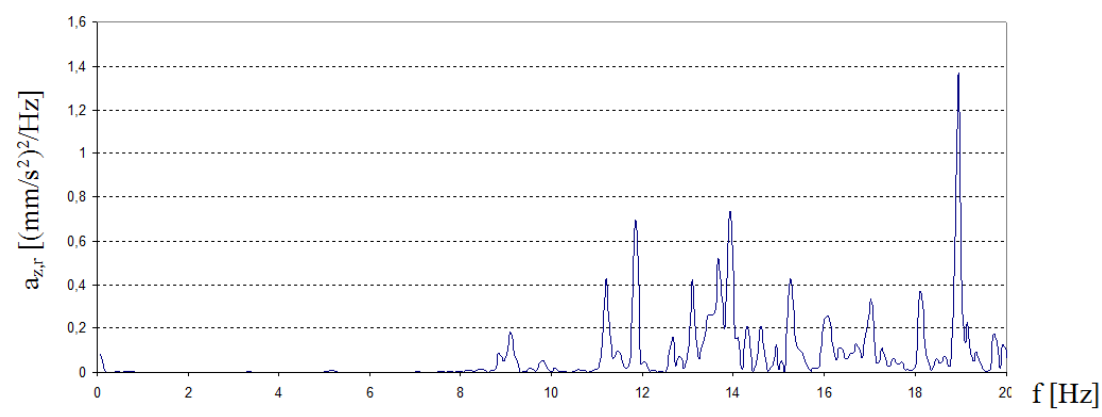

Figure 7: PSD vibration acceleration $\left(\mathrm{G}_{\mathrm{M} 1 \mathrm{M} 1}(\mathrm{f})\right)$ in $\mathrm{M} 1$ - $\mathrm{Z}$ 


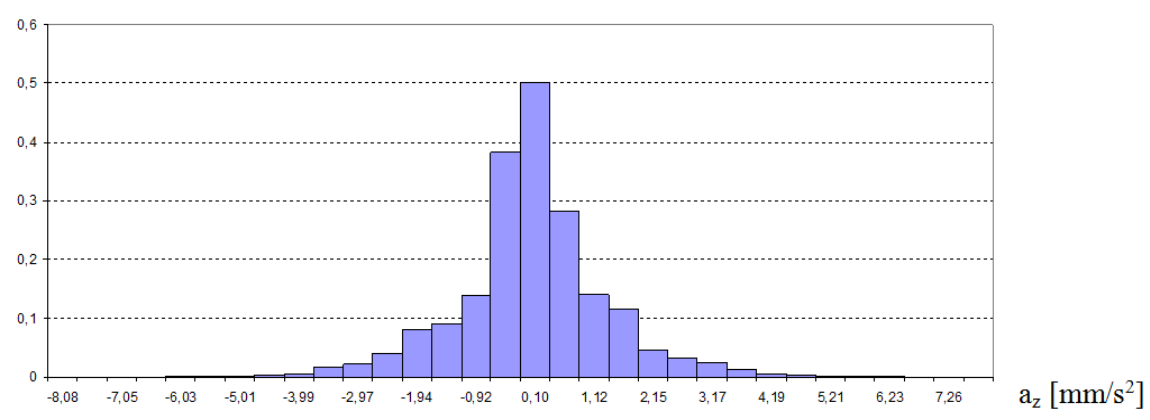

Figure 8: Histogram time record of vibration acceleration in $\mathrm{M} 1$ - Z

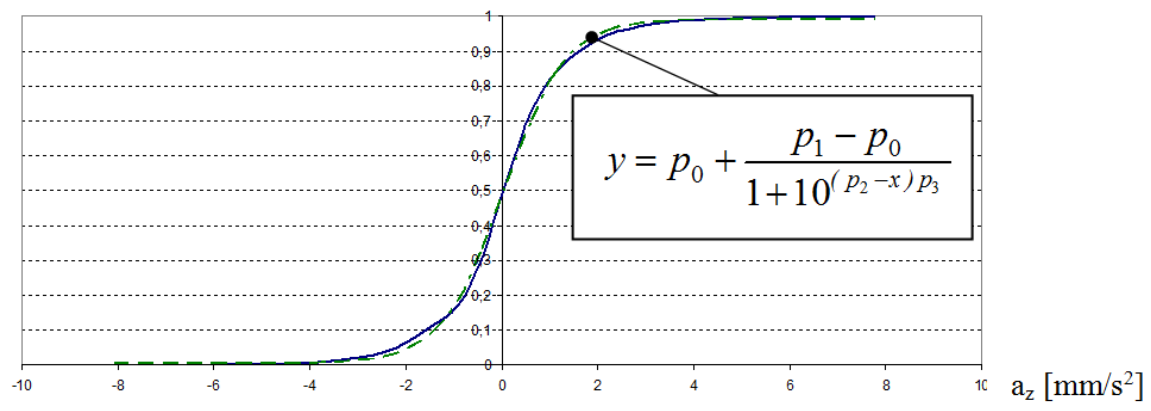

$p_{0}=0,00521879832, p_{1}=0,9930346093 p_{3}=0,0451066486, p_{3}=0,675454548$

Figure 9: Distribution function of the vibration acceleration time record in $\mathrm{M} 1-\mathrm{Z}$

Random vibration analyses enable the determination of the response of the system to excitation vibrations, which are not deterministic in nature. Such excitation effects can be described statistically (middle quadratic variation, root mean square, etc.).

Excitation is applied in the form of power spectral density PSD, which determines the spectral values with respect to frequencies, thus capturing the frequency range. The resulting output is statistical in nature and represents that $99,737 \%$ of the time response, produce values less than the standard deviation, [5].

Figure 10 illustrates the calculated maximum deflection, velocity and acceleration at the point corresponding to experimental measurements at point M3 (roof). 

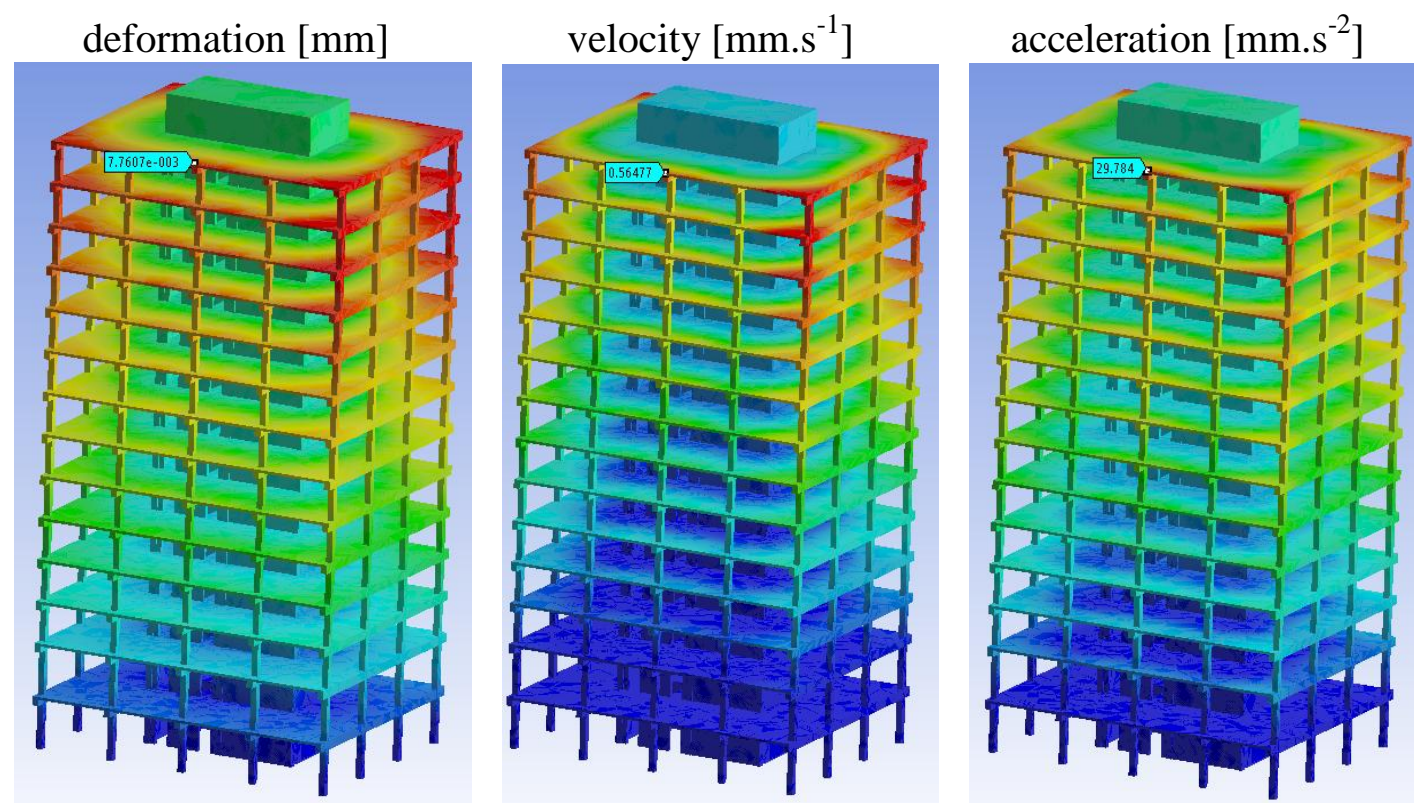

Figure 10: Deformation, velocity and acceleration in M3

Confronting theoretically calculated RPSD (RPSD - Response Power Spectral Density) with experimentally obtained RPSD, the observed point - M3 (roof) is shown in figure 11. By comparing the RPSD it can be said that this method of calculating the response of the structure from the experimentally observed load effects observed in RPSD theory showed some dominant frequency bands that corresponded to the experimental RPSD. In this case it involves a frequency at $8,76 \mathrm{~Hz}$, then at $11,8 \mathrm{~Hz}$, respectively in the $13 \mathrm{~Hz}$ to $14 \mathrm{~Hz}$, and also in the $16,5 \sim 17,1 \mathrm{~Hz}$ range.

Comparison of the results of the dynamic response based on the theoretical and experimental approach can be implemented on the basis of the observed RMS vibration acceleration (RMS $\left.=\mathrm{x}_{\mathrm{ef}}\right)$ at point M3:

$\mathrm{RMS}_{\text {exper }}=6,81261 \mathrm{~mm} \cdot \mathrm{s}^{-2}$;

$\mathrm{RMS}_{\text {teor }}=9,9726 \mathrm{~mm} \cdot \mathrm{s}^{-2}$.

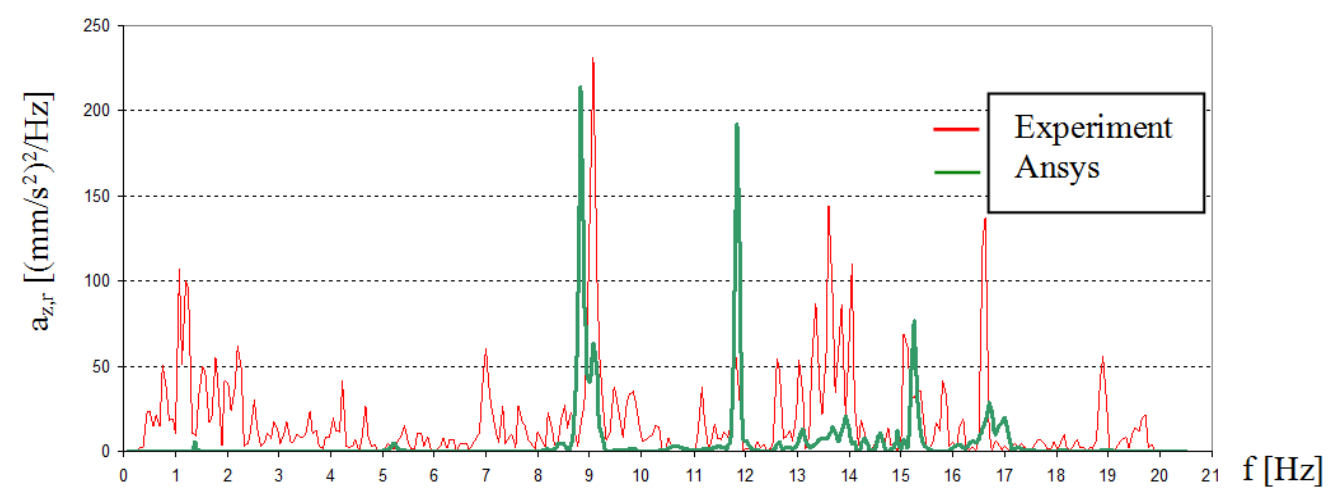


Figure 11: Comparison of response spectra power spectral density vibration acceleration at point M3 - direction $\mathrm{Z}$

\section{Conclusion}

This case involves a calculation of the dynamic response of the structure by a randomly acting ballast effect represented by the experimentally observed PSD load vibration acceleration of the reference object position.

The application of this method confirms that the presented random frequency analysis is a suitable method for modelling the effects of random excitations and dynamic responses of the structure.

Those procedures can also disclose results at any point of the structure (deformation, velocity, acceleration, internal forces and stress) including places where dynamic responses of the structure were not experimentally observed.

The presented method facilitates the determination of responses during the design phase in order to reveal actual excitation of dynamic effects not only by rail, which could previously only be obtained from experimental measurements during on-site construction.

\section{Acknowledgements}

The paper presents results of the research activities of the Centre „Progressive Constructions and Technologies in Transportation Engineering“. The Centre was supported by the Slovak Research and Development Agency under the contract No. SUSPP-0013-09 and the companies Inžinierske stavby and EUROVIA SK.

The paper is carried out within the project No. 1/0321/12, partially founded by the Science Grant Agency of the Ministry of Education of Slovak Republic and the Slovak Academy of Sciences.

\section{References}

[1] Benčat J. (1996). Investigation of Trafic Ground Vibrations by Random Process Theory. In: Vehicle-Infrastructure Interaction IV, San Diego. USA.

[2] Benčat J. (1986). Application of Probabilistic Processes in Investigation of Microtremor due to Traffic. In: Proc. $8^{\text {th }}$. European Conference on Earthquake Engineering, Part 4. Lisbon. Portugal.

[3] Li J. \& Chen J. (2009). Stochastic Dynamics of structures. John Wiley and Sons.

[4] Makovička D. \& Makovička D. (2009). Response Analysis of Building under Seismic Effects of Railway Transport. In: Engineering Mechanics 2009. National Conference with International Participation, Svratka, Czech Republic.

[5] Simiu E. (2010). Chaotic Transitions in Deterministic and Stochastic Dynamical System. Princeton University Press. Princeton an Oxford. 